\title{
Instruments Available to The Melter on The Melt Floor
}

\author{
by Larry Smith
}

The melting equipment at Oklahoma Steel Castings Co. is a 2-tph acid lined, top charge CQT Lectromelt furnace, in which we produce $8400-1 b$ standard size heats. In this paper, I will discuss some of the instruments available to the melter on the floor.

\section{WEIGHING DEVICES}

Three types of scales are used to weigh the charge, alloys, and other addition. A heavy platform scale is used to weigh the foundry returns and purchased plate scrap. This scale has a 7-ton capacity.

Two sets of smaller scales with $1000-\mathrm{Ib}$ capacity are used to weigh all the alloys and other additions to the charge. These scales are checked with standard weight daily. One set of $1-\mathrm{oz}$ to $10-1 \mathrm{~b}$ scales is used to weigh all the small items.

It is very important to use scales suitable for the job.

\section{SPEEDY MELT-DOWN CARBON}

The melt-down carbon is obtained by using standard size charges of $50 \%$ foundry returns and $50 \%$ plate scrap. Before charging the furnace, about $110 \mathrm{lb}$ of pea-size anthracite coal is placed in the bottom of the furnace and the furnace is charged.

The oxygen-natural gas torch is used to speed up the melt-down. This helps to produce an oxidizing bath so that, normally, no iron ore is used in the charge. This gives about 35 to 40 points of carbon to be removed from the bath with oxygen injection.

The proper ratio of the cubic feet of natural gas flow to oxygen consumption is maintained by the use of flow meters. We have determined by calculations and actual experience the optimum setting for both gases.

LARRY J. SMITH is melting superintendent, Oklahoma Steel Castings Co., Tulsa, Okla.

\section{CARBON ANALYSIS}

When the bath has reached approximately $2850^{\circ} \mathrm{F}$ and is ready for oxygen injection, a steel sample is taken for a carbon determination on the Fisher carbanalyzer. This sample is dipped from the furnace and poured into a chill mold for a pin $1 / 2$ in. in diameter and $43 / 4$ in. long to test the carbon content in order to determine the length of oxygen blow.

After the blow, a waiting period of $1 \mathrm{~min}$ is allowed to give the bath time to settle down and for the flowing current to stir the metal. A spoon sample is taken from the bath, a carbanalyzer pin is poured, and a 4-mm diameter pin test is taken with a pyrex tube. The $4-\mathrm{mm}$ pin test is sent to the laboratory through an air tube.

There are two methods of taking the 4-mm diameter pin test; one is a purchased vacuum tube held by a pair of tongs, one end is put into the molten metal. The glass melts and the vacuum sucks the tube full of metal. This costs about 18 cents per test; the other method is using a rubber bulb with a pyrex tube 4$\mathrm{mm}$ ID, 48 in. long. The bulb is compressed, the tube is put into the molten metal, and then the bulb is slowly released. This sucks the metal into the tube. The length of the pin depends on how much the bulb is compressed; usually a 6-in. pin is taken. This costs about .02 cents per test.

After the chemist receives the pin, a sample is cut from the middle of the pin with a rapid cut-off machine which has two friction saw blades that are set to cut a sample weighing $0.950 \mathrm{~g}$. The carbon is run on a Leco carbon machine. The chemist calls the results on a field phone to the melter; this takes approximately $4 \mathrm{~min}$ from the time the test is set until the results are returned. With this information, the carbon is adjusted and the temperature is checked with the immersion thermocouple. If the metal has reached the desired temperature, the heat is then tapped.

If there are five or more points difference between the laboratory report and the carbanalyzer reading, the heat is rechecked to determine the exact carbon, or if this disagreement is due to alloy, faulty test material, or faulty equipment.

\section{PROGRAMMED MELTING USING KW-HR METER}

When the furnace is charged, the kilowatt meter is set at zero and the power turned on, on high tap, and an oxygen-natural gas torch is put in the furnace. The torch is used to supplement melting for approximately $25 \mathrm{~min}$ and then is removed if the charge is completely melted in. At this point there is about $1000 \mathrm{kw}$ $\mathrm{hr}$ on the meter. The furnace is left on high tap until approximately $1160 \mathrm{kw}-\mathrm{hr}$ is reached, then is taken over to No. 2 tap.

When the kilowatt meter reaches about $1300 \mathrm{kw}-\mathrm{hr}$, the bath will have started a light boil and the temperature will be about $2850^{\circ} \mathrm{F}$. At this time, oxygen is injected to reduce the carbon. After the blow period, the power is turned on low tap and the carbon and temperature check is made. If the carbon is in range and the desired temperature is reached, the heat is then tapped. The kilowatt reading then is approximately 1500 kw-hr.

The ammeter chart is used with the kilowatt meter in programming the heat. The ammeter is hooked up on primary circuit and is watched closely by the melter before he changes from high tap to No. 2 tap to make certain the bath is working right, and just before the blow period to make certain that the bath has started a boil and is ready for oxygen injection.

In this paper I have described some of the instruments available to the melter and how they are used at Oklahoma Steel Castings Co. This has helped us to produce better quality steel, with closer control of the chemistry. 